\title{
Sensitivity of boreal-summer circulation and precipitation to atmospheric aerosols in selected regions - Part 2: The Americas
}

\author{
E. M. Wilcox, Y. C. Sud, and G. Walker \\ Laboratory for Atmospheres, NASA/Goddard Space Flight Center, Greenbelt, MD, USA
}

Received: 1 April 2009 - Revised: 21 July 2009 - Accepted: 10 September 2009 - Published: 23 October 2009

\begin{abstract}
Aerosol perturbations over selected land regions are imposed in Version-4 of the Goddard Earth Observing System (GEOS-4) general circulation model (GCM) to assess the influence of increasing aerosol concentrations on regional circulation patterns and precipitation in four selected regions: India, Africa, and North and South America. Part 1 of this paper addresses the responses to aerosol perturbations in India and Africa. This paper presents the same for aerosol perturbations over the Americas. GEOS-4 is forced with prescribed aerosols based on climatological data, which interact with clouds using a prognostic scheme for cloud microphysics including aerosol nucleation of water and ice cloud hydrometeors. In clear-sky conditions the aerosols interact with radiation. Thus the model includes comprehensive physics describing the aerosol direct and indirect effects on climate (hereafter ADE and AIE respectively). Each simulation is started from analyzed initial conditions for 1 May and was integrated through June-July-August of each of the six years: 1982-1987 to provide a 6-ensemble set. Results are presented for the difference between simulations with double the climatological aerosol concentration and one-half the climatological aerosol concentration for three experiments: two where the ADE and AIE are applied separately and one in which both the ADE and AIE are applied. The ADE and AIE both yield reductions in net radiation at the top of the atmosphere and surface while the direct absorption of shortwave radiation contributes a net radiative heating in the atmosphere. A large net heating of the atmosphere is also apparent over the subtropical North Atlantic Ocean that is attributable to the large aerosol perturbation imposed over Africa. This atmospheric warming and the depression of the surface pressure over North America contribute to a northward shift of the inter-Tropical Convergence Zone over northern South
\end{abstract}

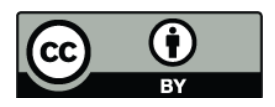

Correspondence to: E. M. Wilcox (eric.m.wilcox@nasa.gov)
America, an increase in precipitation over Central America and the Caribbean, and an enhancement of convergence in the North American monsoon region.

Keywords. Atmospheric composition and structure (Aerosols and particles; Cloud physics and chemistry) - Meteorology and atmospheric dynamics (General circulation)

\section{Introduction}

The radiative impacts of aerosols can affect regional circulation patterns and their related hydrological cycling. Chung et al. (2002) impose the observed winter season aerosol radiative forcing on the Indian Ocean in a global model and report a reduction in winter precipitation over India. During the spring and early summer the clear-sky radiative forcing of dust and soot aerosols provides an elevated heat source over the Indo-Gangetic Plain of India that promotes the onset of the summer monsoon and increases precipitation in Northern India (Lau and Kim, 2006; Lau et al., 2006). Yoshioka et al. (2007) attribute a portion of reduced precipitation along the inter-Tropical Convergence Zone (ITCZ) over Africa to the clear-sky aerosol radiative forcing, while Rotstayn and Lohman (2002) report a reduction in Sahel precipitation in response to the cloud radiative effect resulting from the entrainment of pollution over the North Atlantic Ocean and the accompanying modification of cloud cover and cloud microphysical processes.

Little is yet known regarding the response over North and South America to the radiative impacts of aerosols. The smoke that accompanies forest and agricultural fires during the austral winter dry season is significantly absorbing (single scatter albedo approximately 0.9, Dubovik et al., 2002) and act as efficient cloud condensation nuclei (CCN; Hobbs and Radke, 1969; Kaufman and Fraser, 1997). The absorbing nature of biomass burning aerosols contributes a significant

Published by Copernicus Publications on behalf of the European Geosciences Union. 
Table 1. Synopsis of simulation experiments.

\begin{tabular}{cccc}
\hline Experiment\# & $\begin{array}{c}\text { Aerosol anomaly in selected regions: } \\
\text { 2X or 1X or 1/2X of } \\
\text { climatological values }\end{array}$ & $\begin{array}{c}\text { Aerosol Direct } \\
\text { Effect (ADE) } \\
\text { On/Off }\end{array}$ & $\begin{array}{c}\text { Aerosol Indirect } \\
\text { Effect (AIE) } \\
\text { On/Off }\end{array}$ \\
\hline 1 & $1 \mathrm{X}$ & on & on \\
$2 \mathrm{a}$ & $2 \mathrm{X}$ & on & on \\
$2 \mathrm{~b}$ & $1 / 2 \mathrm{X}$ & on & on \\
$3 \mathrm{a}$ & $2 \mathrm{X}$ & on & off \\
$3 \mathrm{~b}$ & $1 / 2 \mathrm{X}$ & on & off \\
$4 \mathrm{a}$ & $2 \mathrm{X}$ & off & on \\
$4 \mathrm{~b}$ & $1 / 2 \mathrm{X}$ & off & on \\
\hline
\end{tabular}

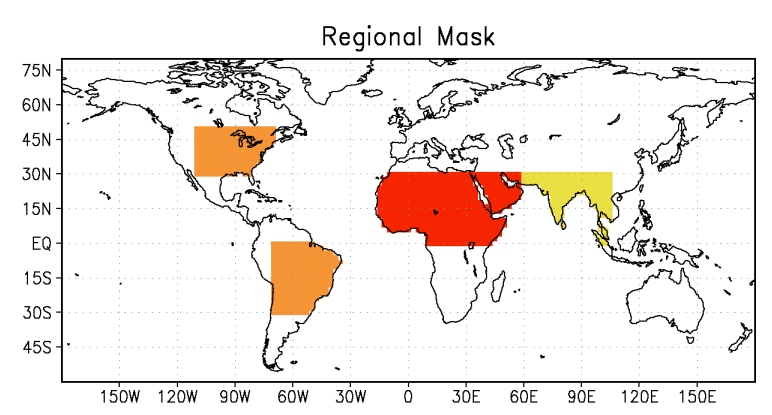

Column Aerosol Optical Depth (GOCART)
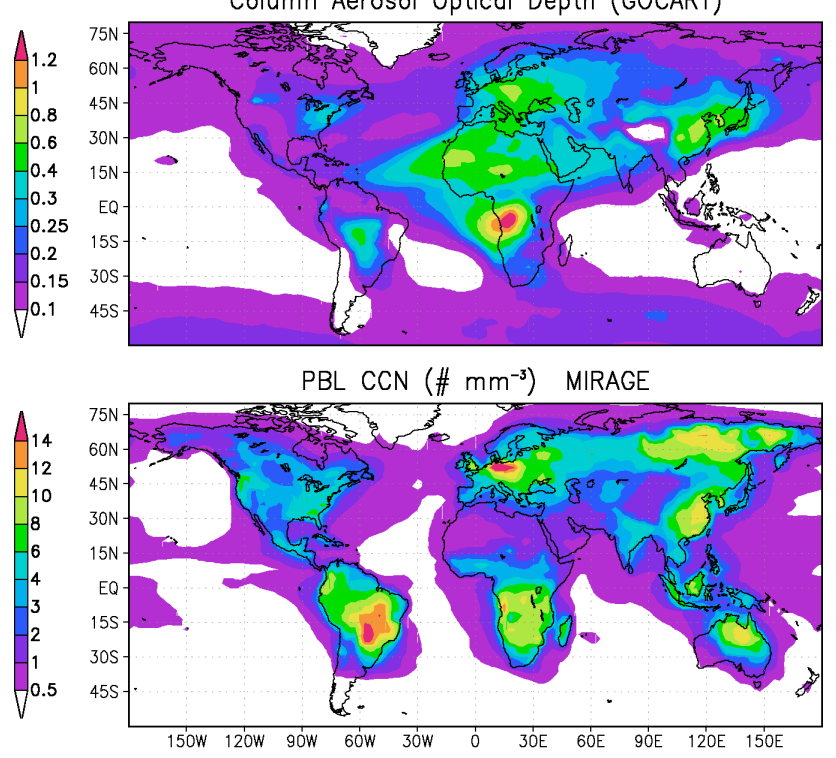

Fig. 1. Regions over which aerosol amounts are perturbed (top), Column aerosol optical depth from GOCART climatology (middle; Chin et al., 2002) used in ADE calculation, boundary layer CCN concentration from the MIRAGE climatology (bottom; Easter et al., 2004) used in the AIE calculation.

atmospheric heating and surface cooling which should induce a significant response in the surface energy balance and lower tropospheric stability. This can potentially yield sig- nificant increases or decreases in cloud cover depending on the level of smoke loading (Koren et al., 2008). Zhang et al. (2008) use a regional climate model to simulate the combined direct and indirect effects of smoke over South America and find that smoke, and dynamical changes in cloud cover attributable to the smoke, delays the onset of the wet season and enhances moisture convergence and cloud cover upwind of the smoke region at the expense of the local moisture convergence.

Under clear-sky conditions, aerosols scatter and absorb solar radiation. The scattering effect cools the column by approximately similar magnitudes at the top of the atmosphere (TOA) and surface (Haywood et al., 1999). The absorbing effect yields a warming in the atmospheric layer at which the absorbing aerosol resides and yields a cooling of nearly equal magnitude at the surface (Haywood et al., 1999; Ramanathan et al., 2001). These scattering and absorption effects of aerosols are typically referred to as the aerosol direct effect (ADE). Aerosols entrained into clouds can modify the microphysical properties of the cloud if the aerosol particles act as CCN. A host of radiative consequences have been proposed to result from this interaction, commonly referred to as the indirect effects or (AIE). Assuming the same amount of condensed water is created by cloud dynamics, an environment that activates a greater number of $\mathrm{CCN}$ will have smaller drops and a greater albedo (Twomey, 1974; Hobbs, 1999; Wilcox et al., 2006; and others). Smaller drop sizes inhibits the collision coalescence of liquid drops and thereby inhibits rainfall. This can lead to a radiative impact by increasing the lifetime of the cloud (Albrecht, 1989). An additional process by which aerosols motivate a cloud radiative impact is the semi-direct effect, whereby the ADE changes the stability of a cloud layer, resulting in a change (usually a reduction) in cloud cover (Hansen et al., 1997).

The net effect of aerosols on climate may result from complex nonlinear interactions between the aerosol radiative perturbation, clouds, and the regional circulation. For example, where aerosol processes affect the vertical temperature profile of the atmosphere, that in turn influences 
Table 2. Energy and water flux differences $2 X$ minus $1 / 2 X$ climatological aerosol amount for North and South America.

\begin{tabular}{|c|c|c|c|c|}
\hline \multirow{2}{*}{$\begin{array}{l}\text { Difference fields ( } 2 \mathrm{X} \text { minus } \\
1 / 2 \mathrm{X} \text { ) aerosol simulations }\end{array}$} & ADE \& AIE (exp. 2) & ADE only (exp. 3) & AIE only (exp. 4) & Nonlinear interactions by difference \\
\hline & N. Amer./S. Amer. & N. Amer./S. Amer. & N. Amer./S. Amer. & N. Amer./S. Amer. \\
\hline Precipitation (mm/mon) & $0.1 /-4.0$ & $-3.7 / 1.0$ & $-1.0 /-3.2$ & $4.8 /-1.8$ \\
\hline Evaporation (mm/mon) & $-1.5 /-4.2$ & $-2.2 /-0.7$ & $-2.1 /-3.7$ & $2.8 / 0.2$ \\
\hline $\begin{array}{l}\text { Moisture Convergence } \\
(\mathrm{mm} / \mathrm{mon})\end{array}$ & $1.4 /-0.1$ & $-1.5 / 1.7$ & $0.8 / 0.1$ & $2.1 /-1.9$ \\
\hline $\begin{array}{l}\text { Sensible heat Flux } \\
\left(\mathrm{W} \mathrm{m}^{-2}\right)\end{array}$ & $-9.0 /-8.1$ & $-4.0 /-5.6$ & $-4.5 /-3.0$ & $-0.5 / 0.5$ \\
\hline Latent heat Flux $\left(\mathrm{W} \mathrm{m}^{-2}\right)$ & $-1.3 /-3.7$ & $-1.9 /-0.6$ & $-1.8 /-3.2$ & $2.4 / 0.1$ \\
\hline TOA Shortwave $\left(\mathrm{W} \mathrm{m}^{-2}\right)$ & $-10.5 /-10.1$ & $-1.2 /-2.1$ & $-10.7 /-9.3$ & $1.4 / 1.3$ \\
\hline $\begin{array}{l}\text { TOA net longwave (out- } \\
\text { going minus incoming; } \\
\mathrm{W} \mathrm{m}^{-2} \text { ) }\end{array}$ & $-1.8 /-2.5$ & $2.3 / 0.2$ & $-4.9 /-4.2$ & $0.8 / 1.5$ \\
\hline TOA Net Radtn. $\left(\mathrm{W} \mathrm{m}^{-2}\right)$ & $-8.8 /-7.6$ & $-3.5 /-2.3$ & $-5.8 /-5.1$ & $0.5 /-0.2$ \\
\hline $\begin{array}{l}\text { Surface Shortwave } \\
\left(\mathrm{W} \mathrm{m}^{-2}\right)\end{array}$ & $-15.9 /-15.1$ & $-5.8 /-8.6$ & $-11.0 /-9.3$ & $0.9 / 2.8$ \\
\hline $\begin{array}{l}\text { Surface net longwave } \\
\text { (outgoing minus incoming; } \\
\mathrm{W} \mathrm{m}^{-2} \text { ) }\end{array}$ & $-5.1 /-3.5$ & $-0.1 /-2.1$ & $-4.0 /-2.8$ & $-1.0 / 1.4$ \\
\hline $\begin{array}{l}\text { Surface Net Radtn. } \\
\left(\mathrm{W} \mathrm{m}^{-2}\right)\end{array}$ & $-10.8 /-12.6$ & $-5.7 /-6.6$ & $-7.0 /-6.5$ & $1.9 / 0.5$ \\
\hline
\end{tabular}

the thermodynamics of clouds and onset of moist convection. These responses modulate vertical distributions of mass and moisture convergence, further altering the distribution of convection and cloud cover. An illustration of such responses is provided by Lau et al. (2006) who demonstrate how the ADE can strengthen monsoonal circulations through a feedback in the atmospheric water cycle.

While empirical evidence for these effects is mounting, complex nonlinear responses suggest that a complete understanding of the role of these effects in global and regional climate requires a comprehensive numerical model with parameterized physics for the nucleation of liquid and ice cloud particles, bulk cloud microphyics, and interactions between shortwave (SW) and longwave (LW) radiation in the atmosphere with aerosol and cloud particles. Towards this end, Sud and Lee (2007) have provided the implementation and evaluation of a model for aerosol nucleation of clouds for GCMs. Other efforts are ongoing at climate modeling centers to evaluate the regional and global impacts of aerosols (e.g. Ming et al., 2007; Takemura et al., 2005; Lohmann et al., 2007). This paper represents a first set of sensitivity studies designed to investigate the response of climate in several regions to perturbations in the aerosol loading of those regions. Simulations are performed where the summertime climatology of aerosols is halved and then doubled in four regions simultaneously: India, Africa, and North and South America. Part 1 of this paper (Sud et al., 2009) addresses the response to the aerosol perturbations in Africa and India. In Part 2 we address the same for North and South America.

\section{GEOS4 GCM and McRAS-AC aerosol-cloud param- eterization}

This study employs version-4 of the Goddard Earth Observing System atmospheric general circulation model. The simulations were performed using a horizontal resolution of 2.0 degrees latitude $\times 2.5$ longitude, and a total of 55 levels in the vertical with hybrid co-ordinates. A comprehensive AIE parameterization with consistent precipitation microphysics has been implemented in GEOS-4 and evaluated in singlecolumn model simulations of the seasonal cycle of cloud cover at the Dept. of Energy Atmospheric Radiation Measurement Program instrumented site in the United States Southern Great Plains (Sud and Lee, 2007). The AIE subroutines consist of four sub-models comprising i) the Fountoukis and Nenes (2005) scheme for aerosol activation of liquid clouds, ii) the Liu and Penner (2005) scheme for heterogeneous and homogeneous nucleation for ice-cloud particles, iii) the Sud and Lee (2007) precipitation microphysics adapted from Seifert and Beheng (2001) for a coarse resolution GCM, and iv) the Khvorostyanov and Curry (1999a, b) parameterization of the cloud particle effective radius. The AIE parameterization solves for cloud particle number density and effective radius. These parameterizations are integrated into the existing Microphysics of Clouds with Relaxed Arakawa-Schubert (McRAS) scheme for bulk cloud physics and microphysics in coarse-grid GCMs (Sud and Walker, 1999a, b), which determines cloud fraction and cloud condensate mass concentration based on the convective 


\section{Sfc Net SW difference $\left(W \mathrm{~m}^{-2}\right)$}
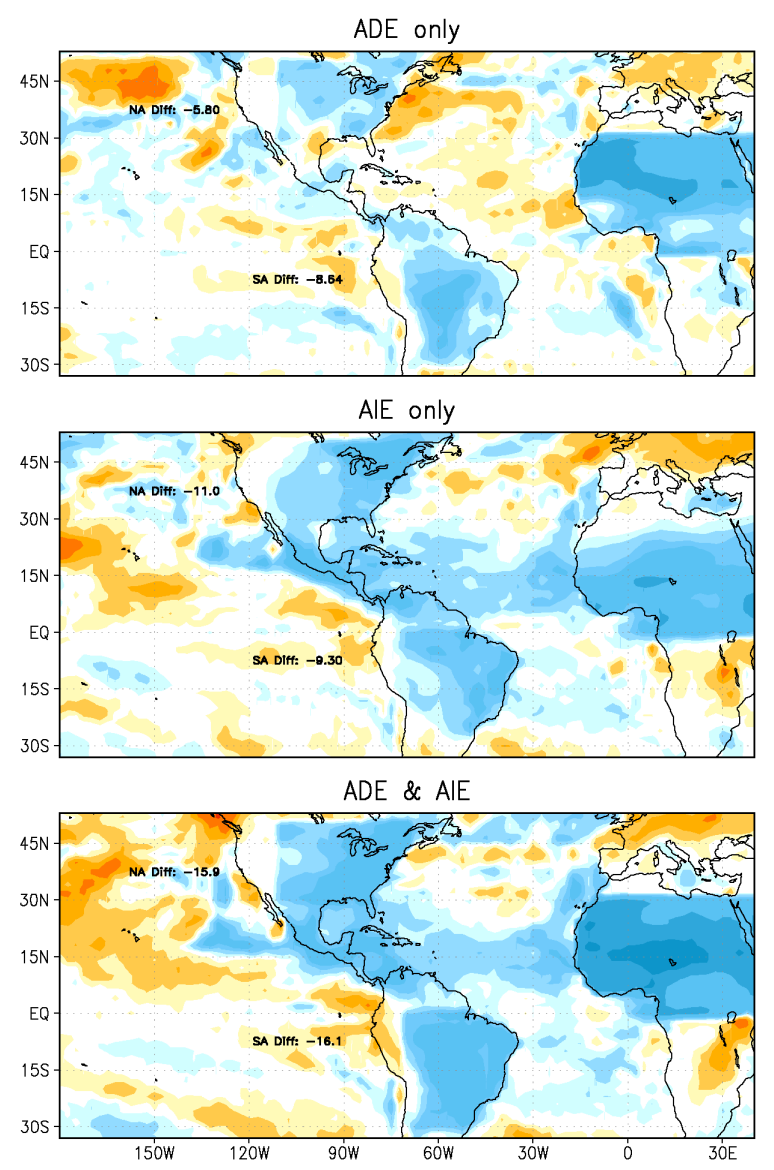

TOA Net SW difference $\left(W \mathrm{~m}^{-2}\right)$

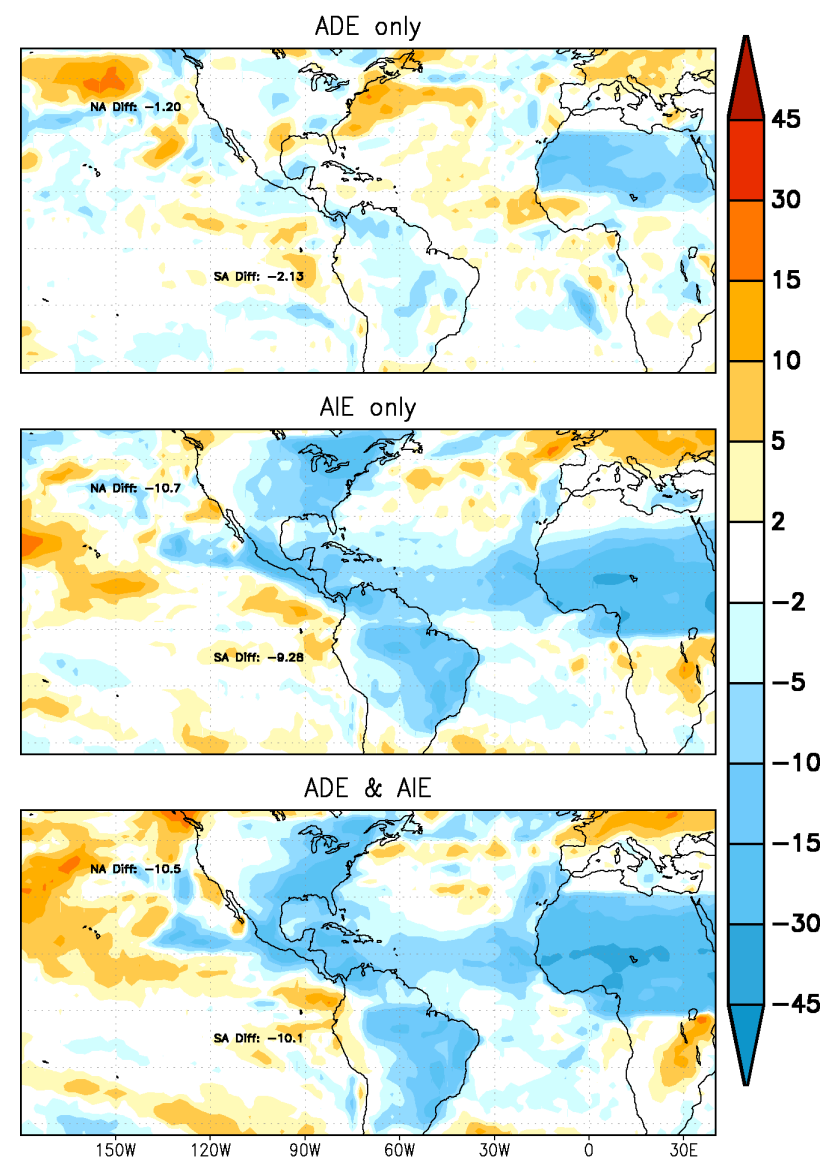

Fig. 2. Difference in net shortwave radiation at surface (left) and top of the atmosphere (right) for doubled minus halved aerosol perturbations in $\mathrm{W} \mathrm{m}^{-2}$. Top panels are for simulations with ADE only, middle panels are for simulations with AIE only and bottom panels are for simulations with ADE and AIE combined.

and large-scale dynamics. The combined McRAS and AIE parameterization is referred to as McRAS-AC. The AIE is computed using the climatology of aerosol particle concentrations from the MIRAGE model (Easter et al., 2004). McRAS-AC currently uses five aerosol species: black carbon, sulfate, dust, organic carbon, and sea salt, but its algorithms are general enough to use any number of aerosols as long as their chemical properties are specified.

The radiative transfer in GEOS-4 is described in Chou and Suarez (1994, 1999). The ADE is included using the optical properties of aerosols prescribed from the monthly aerosol data simulated with the Georgia Institute of TechnologyGoddard Global Ozone Chemistry Aerosol Radiation and Transport (GOCART) model (Chin et al., 2002). These properties assume that the aerosol species are externally mixed.

Further details of the model and the relevant parameterizations can be found in Part 1 of this paper (Sud et al., 2009), Sud and Lee (2007) and the references noted above.

\section{Simulation experiments}

This study focuses on the boreal summer season, which for South America is the dry winter season. Over North America we have selected the region from the Great Plains to the East Coast, which is dominated by moist convective cloud systems and also experiences a rise in aerosol optical thickness in summer (Holben et al., 2001). The dry season over South America exhibits a dramatic rise in smoke concentrations as a consequence of extensive forest burning and low rainfall. Under clear-sky conditions this smoke yields a substantial direct warming of the atmosphere and cooling of the surface. However, the net radiative effect of the aerosols depends strongly on the response of clouds through both the AIE and the semi-direct effect. Koren et al. (2008) find that cloud cover over the Amazon increases with increasing smoke aerosol by suppressing coalescence and rain, but also decreases with increasing aerosol because of semi-direct effect. Which process wins out, they conclude, depends critically on the amount of aerosol and the amount of cloud cover. 


\section{Sfc Net LW difference $\left(W \mathrm{~m}^{-2}\right)$}
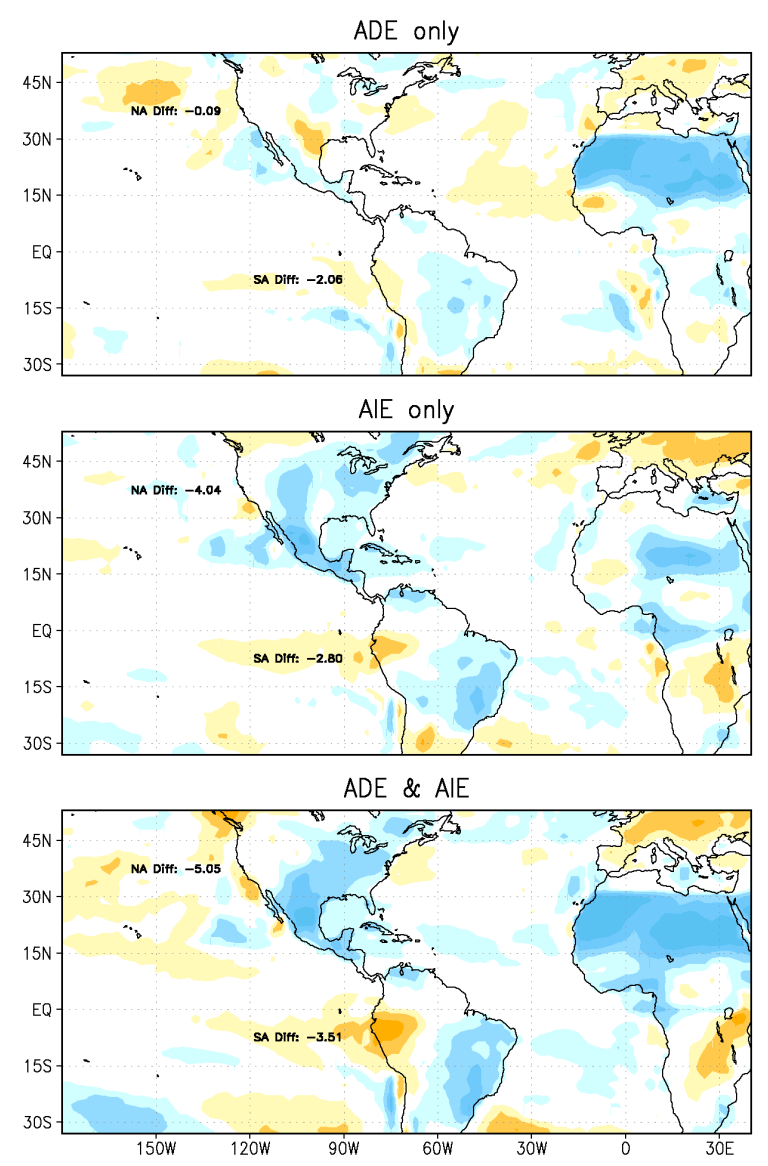

TOA Net LW difference $\left(W \mathrm{~m}^{-2}\right)$

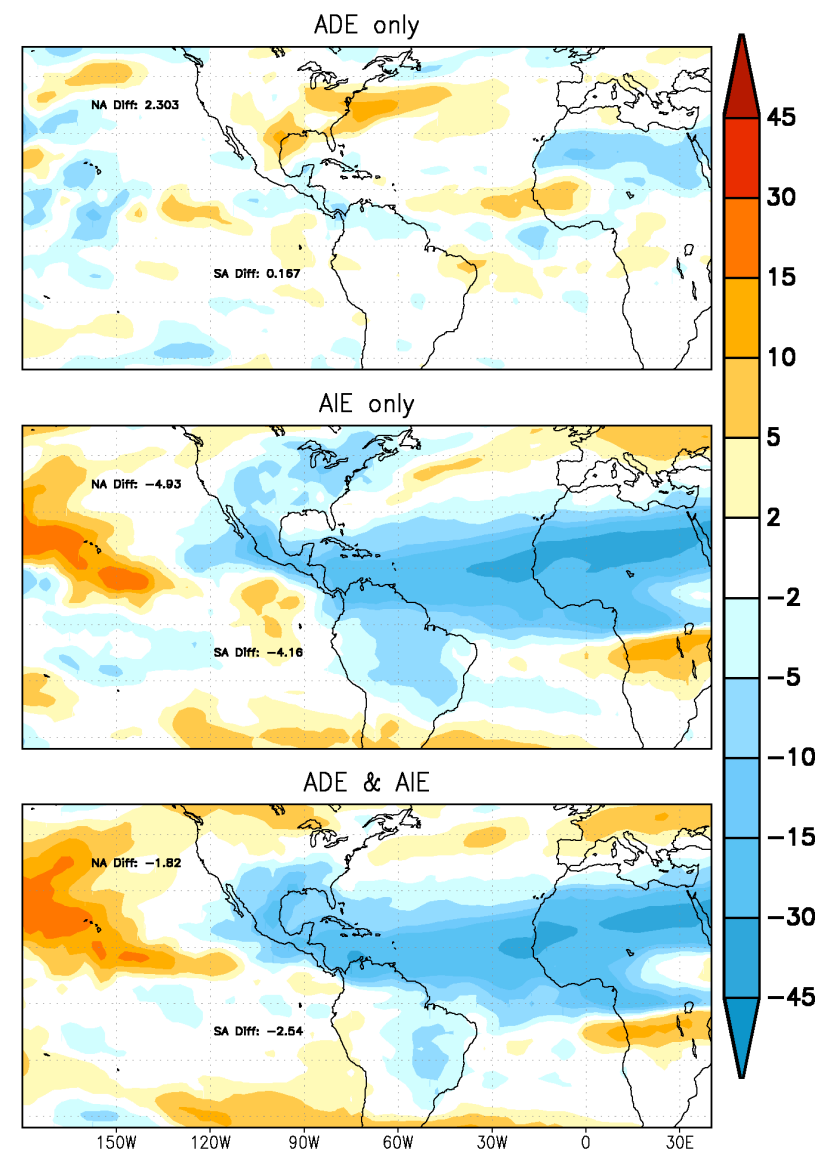

Fig. 3. Same as Fig. 2 for net outgoing longwave radiation at surface (left) and top of the atmosphere (right) in $\mathrm{W} \mathrm{m}^{-2}$.

In addition to the climate response in these specific regions, the combined effect of doubling the aerosol concentrations in these two regions and Africa during the same season yields a strong response in the tropics between North and South America. This response is also the subject of this study.

Note that while the model accounts for the advection of altered cloud fields, the aerosol perturbations are limited to the land regions, therefore there is no accounting for the advection of increased aerosol concentrations in these experiments. In this sense these experiments are sensitivity tests to a radiative perturbation in limited regions that is consistent with an increase in aerosols in that region. Of particular interest in this study is the atmospheric circulation response to the radiative perturbation arising from the forcing attributed to the ADE and AIE in a region.

A summary of the model simulation experiments performed in this study is shown in Table 1. Experiment 1 is a baseline simulation with climatological aerosols. Experiments 2 through 4 comprise 6-member ensembles each of simulations where the aerosol amounts are doubled and halved in the aerosol perturbation regions indicated in Fig. 1.
Both the ADE and the AIE are active in the model in experiment 2, while the AIE and ADE are individually turned off in experiments 3 and 4 respectively. The climate response to these aerosol perturbations is evaluated from the difference between the ensemble mean results of the doubled and halved aerosol perturbation simulations.

All simulations used initial conditions derived from the NCEP reanalysis (Kalnay et al., 1996) interpolated to the GEOS-4 GCM grid for 1 May of each of the six years: 1982 through 1987. Each simulation was integrated to 31 August to provide output to be examined for June-July-August (JJA). The first month (May) is ignored for initial adjustment to the imposed aerosol anomalies and intrinsic model biases. The initial conditions are chosen so that the model is started from a balanced state appropriate for the season. 1 May from each of six different years is used as a convenient means of generating a six-member ensemble with different initial conditions for each ensemble member. This removes some short-term weather and interannual variability from the results. The focus of the study is on the short-term response of the atmosphere to differences in aerosol amount over a single season, 
Sfc Net Radiation difference $\left(W \mathrm{~m}^{-2}\right)$ TOA Net Radiation difference $\left(W \mathrm{~m}^{-2}\right)$
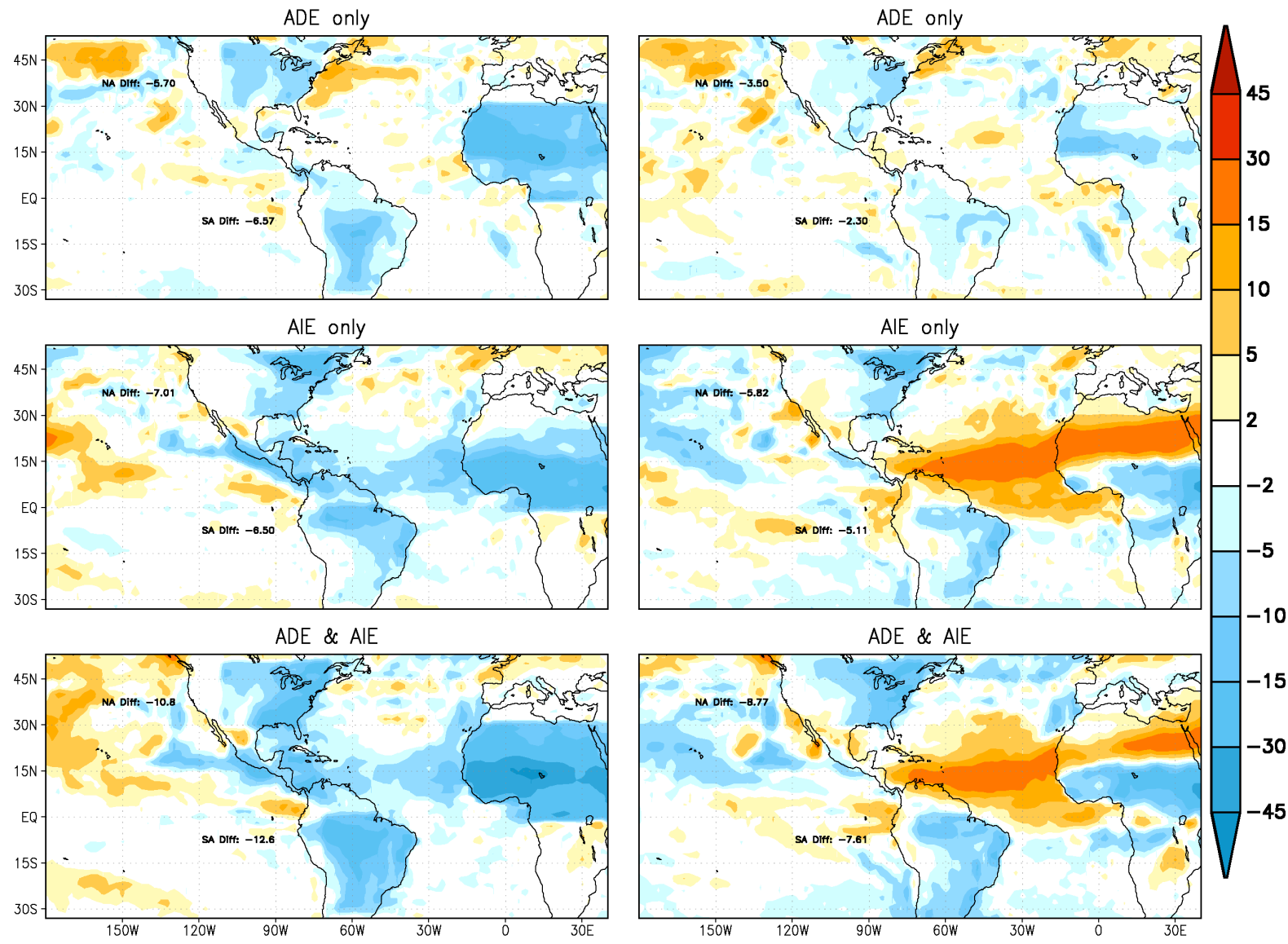

Fig. 4. Same as Fig. 2 for net radiation at surface (left) and top of the atmosphere (right) in $\mathrm{W} \mathrm{m}^{-2}$.

Table 3. Cloud cover differences $2 \mathrm{X}$ minus $1 / 2 \mathrm{X}$ climatological aerosol amount for North and South America ( -0 denotes a decrease of less than $0.5 \%$ ).

\begin{tabular}{lccc}
\hline Difference fields (2X minus 1/2X) aerosol simulations. & $\begin{array}{c}\text { ADE \& AIE (exp. 2) } \\
\text { N. Amer./S. Amer. }\end{array}$ & $\begin{array}{c}\text { ADE only (exp. 3) } \\
\text { N. Amer./S. Amer }\end{array}$ & $\begin{array}{c}\text { AIE only (exp. 4) } \\
\text { N. Amer./S. Amer }\end{array}$ \\
\hline Low cloud (below $700 \mathrm{hPa}$ level) cover $(\%)$ & $1.3 / 2.7$ & $-0 / 0.1$ & $1.8 / 2.4$ \\
mid-level cloud (between 700 hPa and 400 hPa level) cover $(\%)$ & $0.5 / 1.9$ & $-0 / 0.2$ & $1.1 / 2.8$ \\
high cloud (above 400 hPa level) cover $(\%)$ & $-1.0 /-0$ & $-1.0 /-1.0$ & $0.9 / 0.2$ \\
total cloud cover $(\%)$ & $0.2 / 3.2$ & $-2.0 /-0$ & $2.7 / 4.7$ \\
\hline
\end{tabular}

therefore all simulations used prescribed sea surface temperatures based on the Reynolds and Smith (1994) data set obtained from the Hadley Center. Climate responses over longer time scales associated with changes in sea surface temperature attributable to aerosol radiative forcing are not included in these results.

\section{Results}

\subsection{Shortwave (SW) radiative fluxes at the top of the at- mosphere (TOA) and surface}

The aerosol perturbations are limited to the land areas indicated in Fig. 1. These are the regions where the shortwave flux difference attributable to aerosol scattering and increased cloud reflectivity are greatest. The magnitudes of the differences in radiative fluxes and water and energy cycle 
components between doubled and halved aerosol amounts in these regions is summarized in Table 2. The magnitude of the change in net SW radiation at TOA attributable to the $\mathrm{ADE}$ is $-1.2 \mathrm{~W} \mathrm{~m}^{-2}$ and $-2.1 \mathrm{~W} \mathrm{~m}^{-2}$ in $\mathrm{N}$. America and $\mathrm{S}$. America, respectively, while the magnitude of the AIE is substantially greater; $-10.7 \mathrm{~W} \mathrm{~m}^{-2}$ and $-9.3 \mathrm{~W} \mathrm{~m}^{-2}$. Maps of the change in TOA and surface net shortwave radiation are shown in Fig. 2. The change in net SW at the TOA in the experiment with ADE and AIE combined is similar to that of the AIE only experiment. However, the surface net SW reveals that the direct effect of aerosols remains an important process over the Americas in the simulations where the ADE and AIE are combined. In the ADE only simulation the change in net SW at the surface exceeds the change in net SW at the TOA by more than $5 \mathrm{~W} \mathrm{~m}^{-2}$ in both regions owing to atmospheric absorption. The difference in the change in net surface and TOA SW in the combined ADE and AIE experiment is comparable in magnitude. Since cloud absorption of SW radiation is small owing to the high single scattering albedo of clouds, the change in direct absorption of shortwave radiation is attributable to aerosols in the combined ADE and AIE experiment.

While the change in radiative fluxes is largest over the aerosol perturbation regions, the circulation response and the advection of altered cloud fields yields significant changes in the radiative fluxes over the oceans. The circulation response (discussed further below) to the ADE over North America is a weakening of the westerly winds over the mid-latitude Atlantic Ocean (see Fig. 8b discussed further below) and a concomitant reduction in evaporation and cloud cover. Hence there is a substantial increase in net SW radiation over the North Atlantic Ocean directly east of North America. This response is not present in the AIE experiment and is restricted to a smaller portion of the North Atlantic Ocean in the combined ADE and AIE experiment.

\subsection{Longwave ( $\mathrm{LW}$ ) and net radiative fluxes at the TOA and surface}

Longwave (LW) radiative responses in the ADE only experiment (Fig. 3, shown as outgoing minus incoming LW radiation) are largely attributable to changes in temperature and clouds in response to the aerosol SW radiative effect. Sulfate and smoke aerosol particles of North and South America do not significantly absorb in the longwave (LW) owing to their small size. At the TOA, the net LW change in the ADE only experiment is negligible in South America and $2.3 \mathrm{~W} \mathrm{~m}^{-2}$ in North America. This TOA cooling over North America is a consequence of the $2 \%$ decrease in cloud cover shown in Fig. 6 (percent changes in cloud cover are summarized in Table 3). In contrast, the change in LW at the surface in the ADE only experiment is negligible in North America and $-2 \mathrm{~W} \mathrm{~m}^{-2}$ in South America. Unlike over North America, there is no net change in total cloud cover in the ADE only experiment over South America. The SW heat-

\section{Sfc Skin Temperature difference (C)}

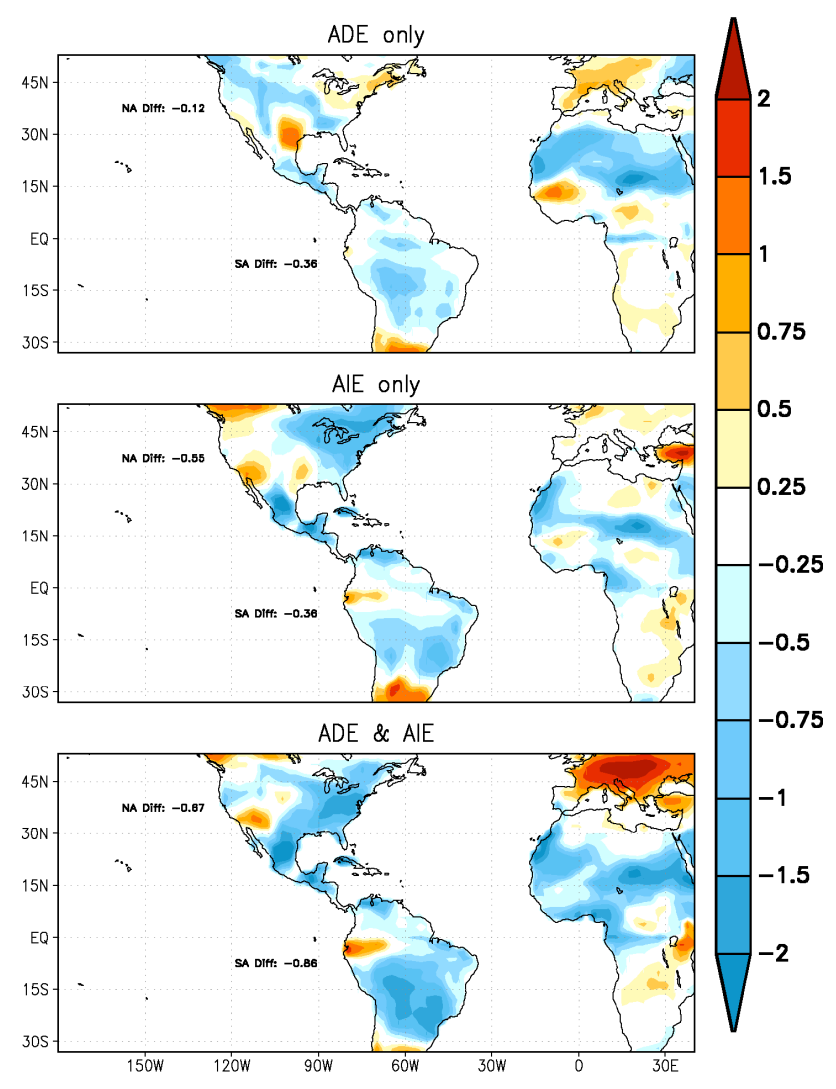

Fig. 5. Same as Fig. 2 for surface skin temperature (in ${ }^{\circ} \mathrm{C}$ ). No change is apparent over ocean because sea surface temperatures are fixed to observed values.

ing owing to solar absorption by smoke in the atmosphere over South America exceeds $6 \mathrm{~W} \mathrm{~m}^{-2}$ in the ADE only experiment. This warming, together with a small increase in low cloud cover ( $<1 \%$; see Fig. 7 and Table 3 ), enhances the downward LW radiation from the lower troposphere to the surface. Also, the decrease in surface temperature reduces the surface emission. Note, however, that the surface LW heating in South America is only one-fourth of the magnitude of the SW cooling from smoke scattering and absorption. The weak low cloud response over South America in the ADE only experiment suggests that the semi-direct effect observed in analyses of satellite data (e.g. Koren et al., 2008) is not driving a significant reduction in cloud cover in this model.

LW heating is apparent at the TOA and surface in the AIE only simulations. In this case it is likely that the increase in CCN yields an increase in low and high cloud cover that both enhances the cloud greenhouse effect and enhances the downward LW radiation to the surface from cloud base. Net outgoing LW at the TOA is $-4.9 \mathrm{~W} \mathrm{~m}^{-2}$ and $-4.2 \mathrm{~W} \mathrm{~m}^{-2}$ over North America and South America respectively in the AIE only experiment. Surface net outgoing 
High-level Cloud Fraction difference

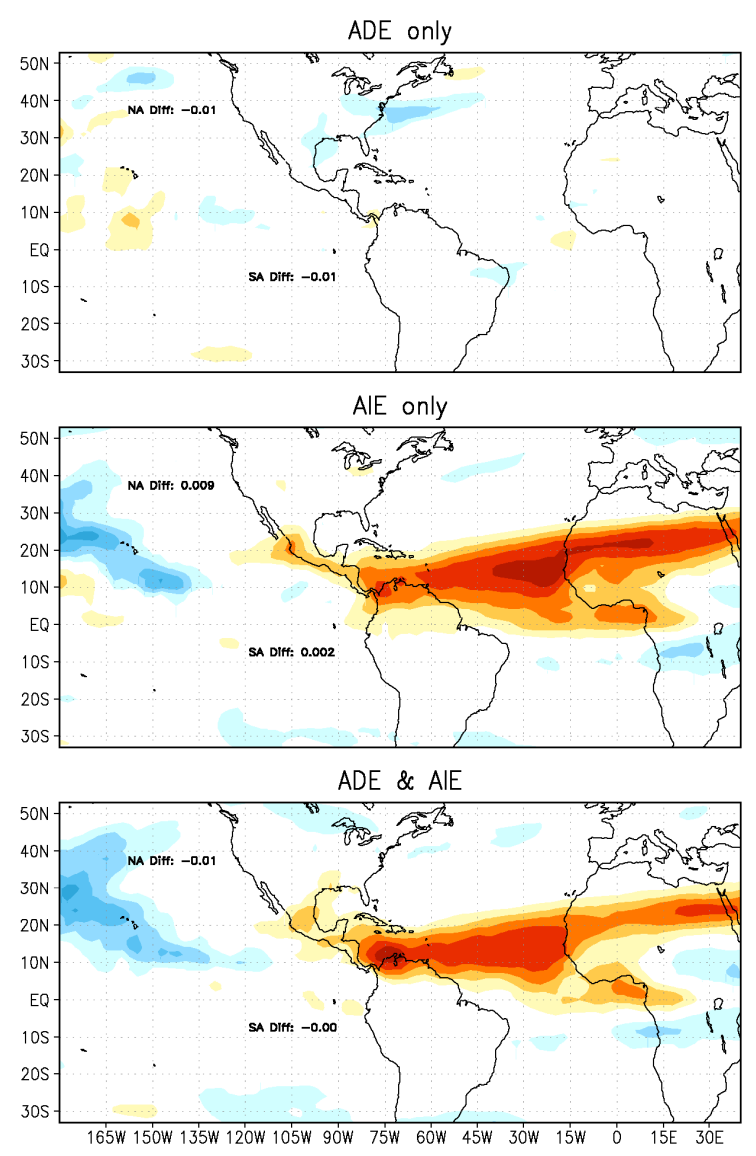

\section{Column Cloud Fraction difference}

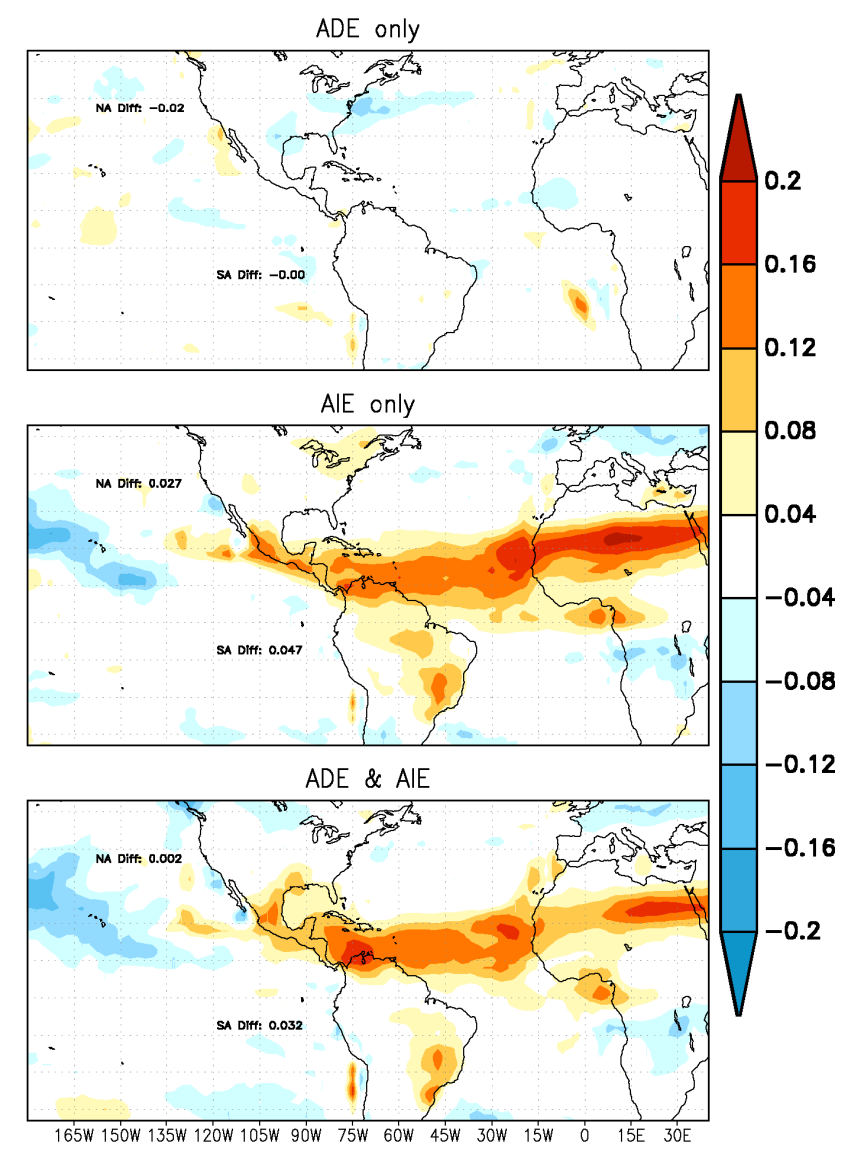

Fig. 6. Same as Fig. 2 for high cloud fraction (left) and column cloud fraction (right). High clouds are clouds at pressure levels less than $400 \mathrm{hPa}$.

$\mathrm{LW}$ is $-4.0 \mathrm{~W} \mathrm{~m}^{-2}$ and $-2.8 \mathrm{~W} \mathrm{~m}^{-2}$, respectively, indicating that in response to the AIE LW heating over North America is absorbed primarily by the surface, while over South America the net LW heating is divided roughly equally between the surface and atmosphere.

An increase in low cloud cover has been hypothesized in studies indicating a positive correlation of aerosol amounts and cloud cover assuming aerosol SW absorption is limited (Kaufman and Koren, 2006). Greater concentrations of CCN yield smaller drops for clouds of the same liquid water content, and inhibit the collision coalescence of raindrops. This suppression of the warm rain process can increase the lifetime, and hence mean coverage, of low clouds (Albrecht, 1989). This process can also invigorate convection leading to more intense convection and an increase in the transport of liquid condensate to the detraining layers of convective clouds (Koren et al., 2005; Rosenfeld and Woodley, 2000). These processes, in addition to any increase in the transport of ice nucleating aerosols, are the primary microphysical causes of increases in cloud amount in simulations with increased aerosol amounts. However, it is important to note that the changes in cloud cover resulting in these simulations are also associated with changes in regional circulation patterns. Evidence of this is present in the substantial changes in LW and SW radiative fluxes over Central America where the aerosol concentrations were not changed, yet substantial changes in the circulation and precipitation are apparent (discussed further below).

In the simulations with combined ADE and AIE, net radiation at the TOA is a cooling over both North and South America (Fig. 4). The magnitudes are $-8.8 \mathrm{~W} \mathrm{~m}^{-2}$ and $-7.6 \mathrm{~W} \mathrm{~m}^{-2}$, respectively. Net radiation at the surface is a greater cooling of $-10.8 \mathrm{~W} \mathrm{~m}^{-2}$ and $-12.6 \mathrm{~W} \mathrm{~m}^{-2}$ for North and South America. The net heating of the atmosphere is smaller than that attributable to shortwave heating in the AIE only experiment reflecting both the modest net LW cooling of the atmosphere in both regions and the fact that the increase in cloud cover attributable to the AIE reduces the magnitude of the ADE when the two effects are combined.

The net radiative cooling at the surface leads to a reduction of the surface temperature (Fig. 5). Since the sea surface temperature is fixed to observed values in these simulations, 


\section{Mid-level Cloud Fraction difference}
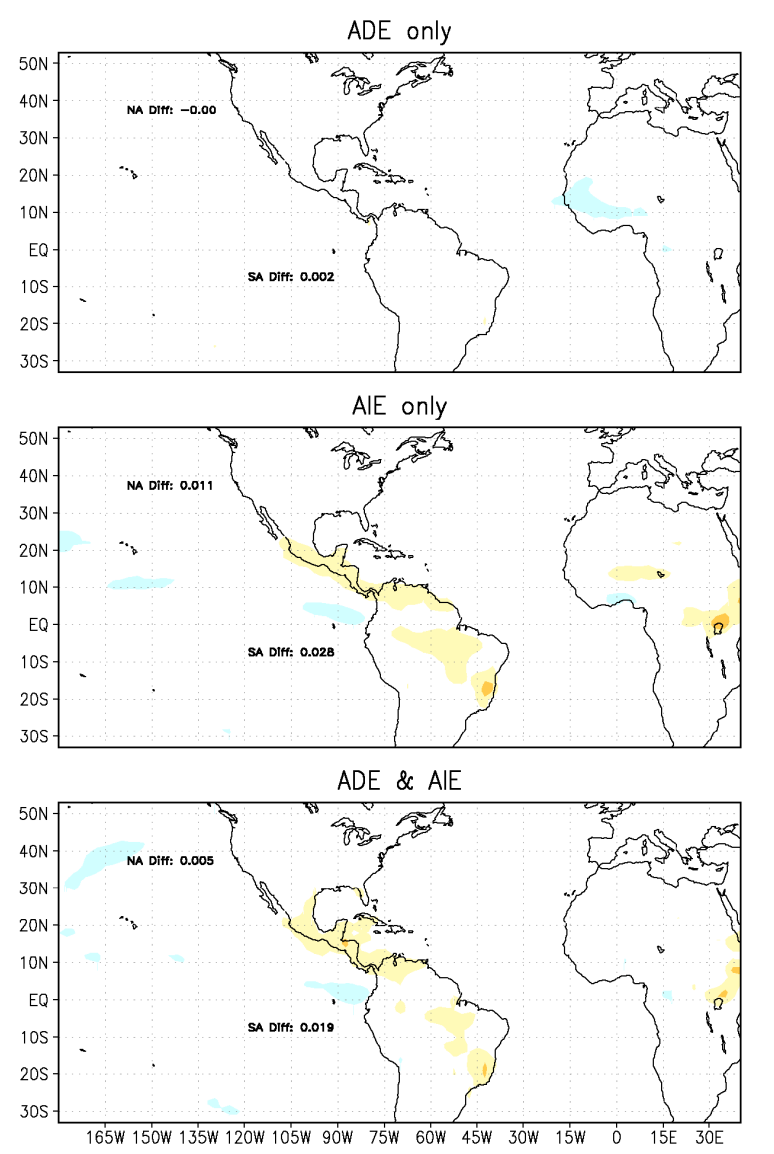

\section{Low-level Cloud Fraction difference}

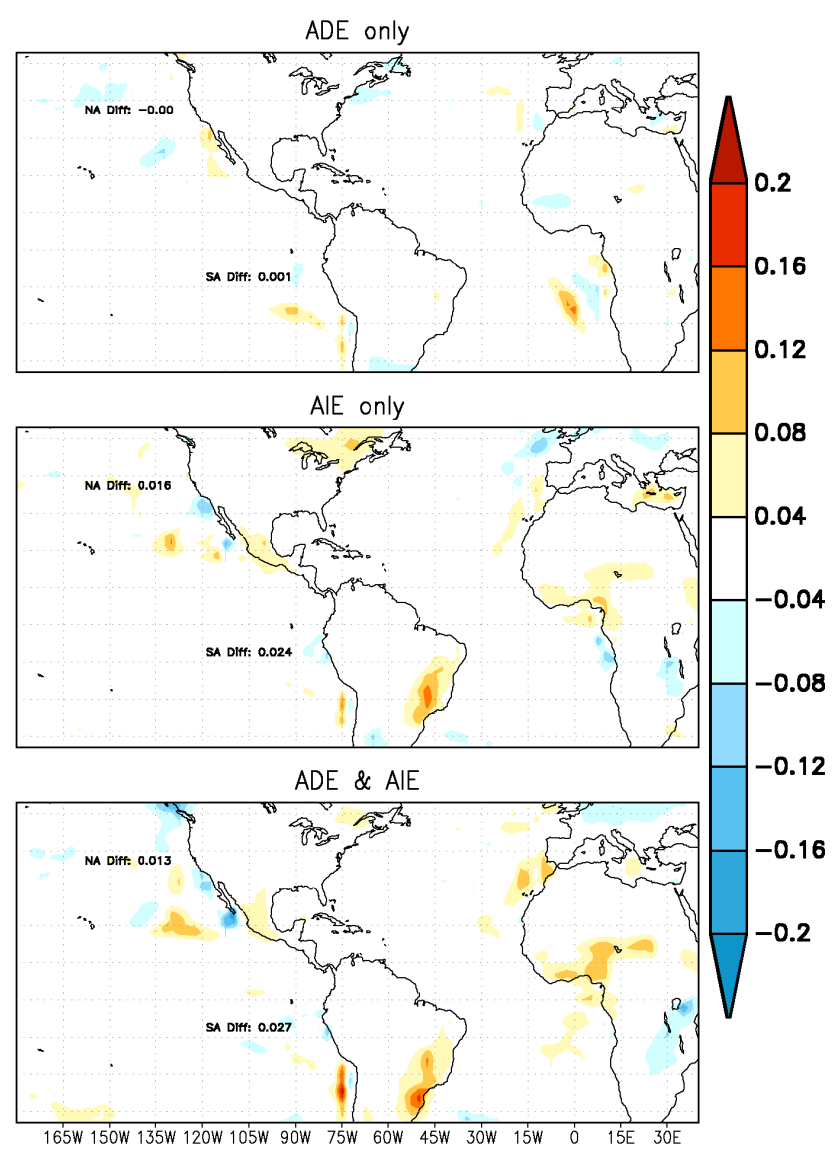

Fig. 7. Same as Fig. 2 for mid-level cloud fraction (left) and low cloud fraction (right). Low clouds are at pressure levels greater than $700 \mathrm{hPa}$. Mid-level clouds occur between 700 and $400 \mathrm{hPa}$.

the reduction in surface temperature is restricted to the land areas. The cooling in the combined ADE and AIE experiment is $-0.67^{\circ} \mathrm{C}$ and $-0.86^{\circ} \mathrm{C}$ in North America and South America, respectively.

In addition to the aerosol perturbations imposed over North and South America, aerosol perturbations are also imposed over Africa and India in the same simulations. The perturbation in Saharan dust over North Africa yields an extended response in the cloud radiative effect over the tropical North Atlantic Ocean attributable to the AIE in the AIE only simulations and the combined ADE and AIE simulations. This forcing is a likely contributor to the circulation and precipitation response in Central America, the Caribbean, and northeastern South America. The net radiative effect of the AIE over the tropical North Atlantic Ocean is a heating of the atmosphere of greater than $15 \mathrm{~W} \mathrm{~m}^{-2}$. Moura and Shukla (1981) show that a heat source north of the equator and a heat sink south of the equator, in the form of sea surface temperature perturbations to the tropical Atlantic Ocean yields a northward displacement of the ITCZ that provides an increase in rainfall over the northernmost portion of South
America and a reduction in precipitation in Northeastern Brazil. A similar pattern for the displacement of the ITCZ is apparent over the Atlantic Ocean and northern South America in the AIE only and combined ADE and AIE simulations here (Fig. 9a discussed further below) which in this case is caused by the net atmospheric heating attributable to the LW component of the AIE over the Atlantic Ocean in response to a large aerosol perturbation over Africa.

The origin of the radiative perturbation over the North Atlantic Ocean is the AIE over Africa. Although cloud cover North of the ITCZ over Africa is low, there is a $10 \%$ to $20 \%$ increase in high cloud cover over Africa resulting from the AIE. This occurs because dust acts as ice cloud nuclei in the McRAS-AC scheme. Strong mixing over the Sahara desert leads to a thick layer of dust in the aerosol climatology. Therefore, in our experiments we have halved and doubled the dust concentration leading to large differences in the number of ice nuclei in the troposphere. In the Sahel and continental ITCZ, additional ice nuclei may be contributed from the vertical transport of dust and other ice nuclei in convective updrafts, which is also a process included 
Sfc Pressure difference ( $\mathrm{hPa}$ )

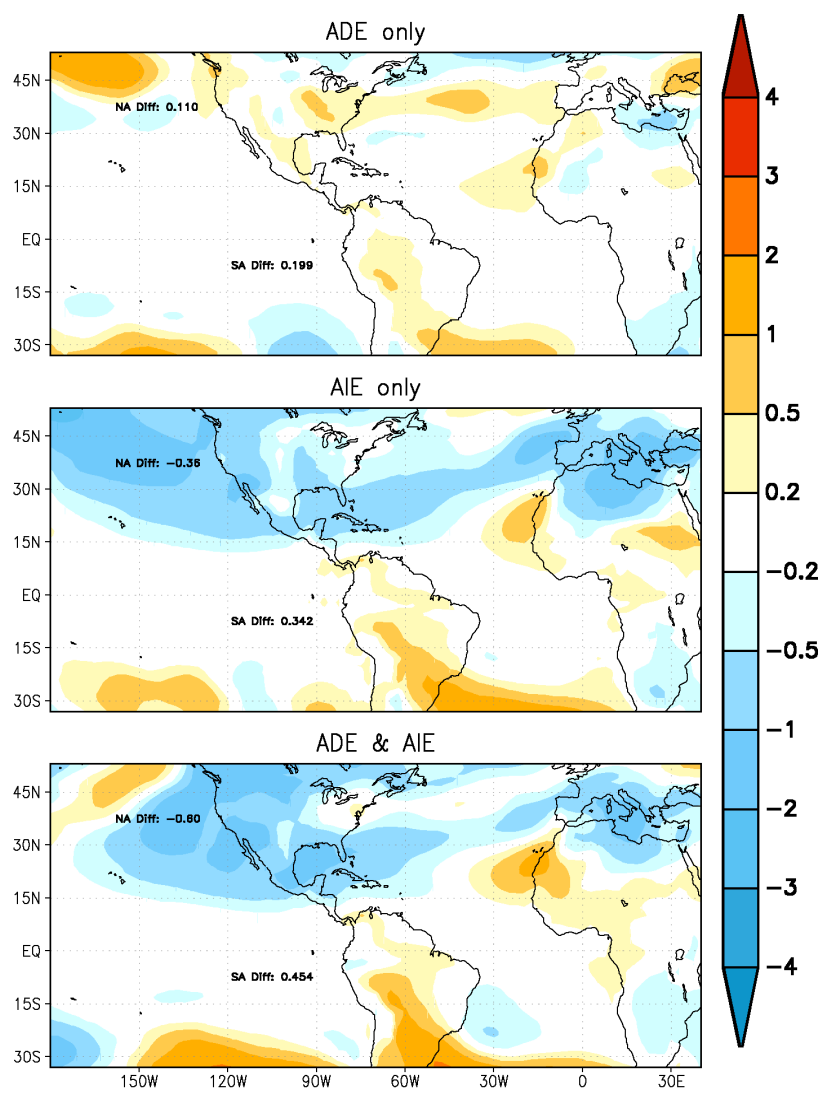

Fig. 8a. Difference in surface pressure for doubled minus halved aerosol perturbations. Top panel is for simulations with ADE only, middle panel is for simulations with AIE only and bottom panel is for simulations with ADE and AIE combined.

in the McRAS-AC scheme. Because of the additional ice nuclei present when the dust concentration is increased, the ice water content of the cirrus clouds is composed of a greater number of smaller ice particles. The growth rate and settling rate of the ice particles both decrease with decreasing particle size. This dependence on particle size means that the cirrus clouds in the simulations with higher dust concentrations persist longer, and mean cloud cover is greater.

The McRAS cloud parameterization also allows for the advection of cloud condensate. The additional high cloud condensate attributable to the AIE over Africa is advected over the Atlantic Ocean owing to the upper-tropospheric winds. Thus, although there is no aerosol perturbation over the Atlantic Ocean in these simulations, the perturbation over North Africa induces a strong radiative perturbation over the ocean. The impact of cloud advection is generally small in GCMs relative to other components of cloud parameterizations. Nevertheless, in a simulation of present-day climate the inclusion of this effect yields more realistic global cloud radiative effects (Sud and Walker, 1999b). Although it is dif-

\section{Sfc Wind difference $\left(\mathrm{m} \mathrm{s} \mathrm{s}^{-1}\right)$}

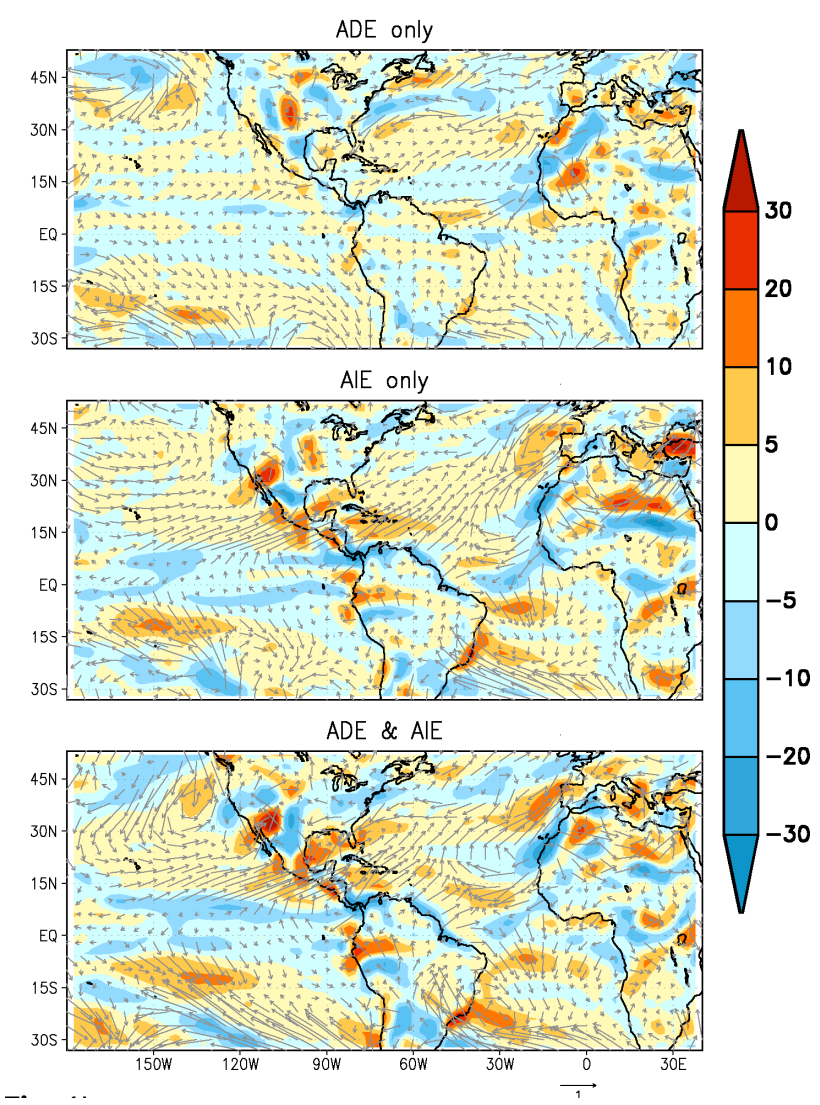

Fig. 8b. Same as Fig. 8 a for $10 \mathrm{~m}$ surface winds with shading indicating convergence (in $10^{-7} \mathrm{~s}^{-1}$ ).

ficult at present to validate cloud advection in the model, we note that the erosion of cloud by mixing of dry air in the cloud layer, as well as evaporation driven by subsidence of the cloud layer or settling cloud particles, are processes included in McRAS-AC that act to limit the duration of ice cloud lifetime. We also note that a 4-times change in the magnitude of Saharan dust loading may be excessive compared to realistic scenarios. The halving and doubling of the aerosol amount in these experiments was done to perform a simple sensitivity study to aerosol perturbations of a significant and plausible magnitude compared to changes in industrial emissions over the modern era. These perturbations were imposed on the dust in the interest of applying the experiment methodology consistently. To the extent that these dust perturbations may be excessive, so too is the response to the dust perturbation described here.

\subsection{Surface pressure and $10 \mathrm{~m}$ surface winds}

The change in surface pressure in the simulations with ADE and AIE combined is the depression of the North American low and enhancement of the high-pressure cells over 

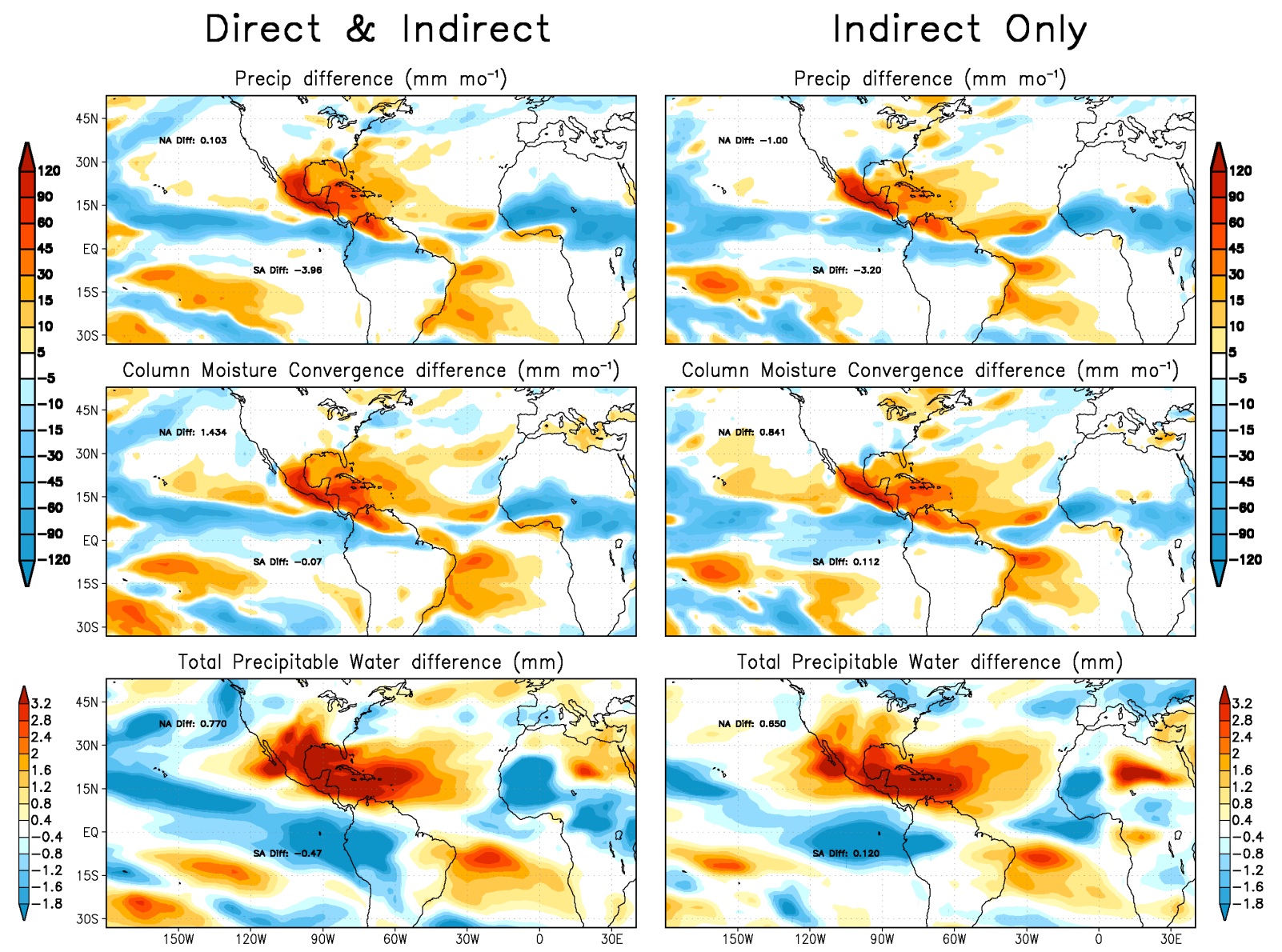

Fig. 9a. Difference between doubled and halved aerosol amounts for precipitation (top), column moisture convergence (middle), and total precipitable water (bottom) for the ADE and AIE combined (left) and the AIE only (right).

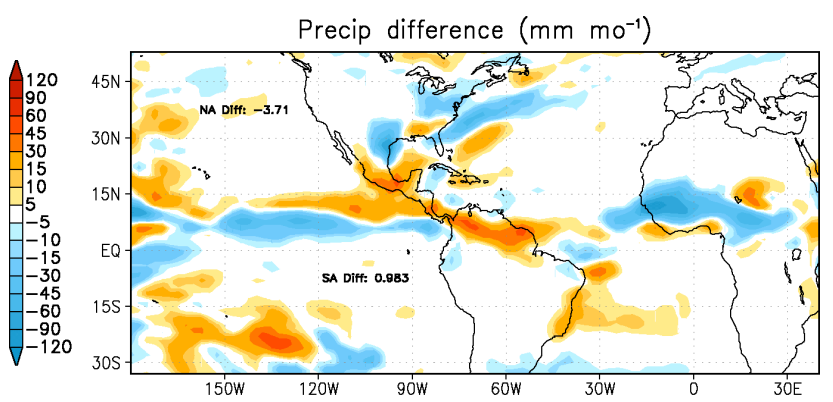

Fig. 9b. Difference in precipitation between doubled and halved aerosol amounts for the ADE only.

the Southeast Pacific and South Atlantic Oceans (Fig. 8a). These reinforce the seasonal patterns of surface pressure indicated in the long-term mean of the NCEP reanalysis (not shown). Over North America, the anomalous low pressure leads to a large southerly wind anomaly along $15 \mathrm{~N}$ (Fig. 8b). This wind anomaly amplifies the North American monsoon circulation in particular, and contributes to anomalous con- vergence over the American Southwest, as well as a large positive precipitation anomaly in Central America (Fig. 9a discussed further below). The subtropical meridional wind anomaly extends across the Americas from the East Pacific Ocean to the West Atlantic Ocean and is likely also responding to the large thermal anomaly over the North Atlantic Ocean attributable to the AIE discussed above and implicated in the precipitation anomaly over South America.

\subsection{Precipitation, moisture convergence, and precip- itable water}

The change in precipitation, column moisture convergence, and precipitable water for doubled minus halved aerosols is shown for the ADE and AIE combined runs and the AIE only runs in Fig. 9a. The precipitation difference for the ADE only experiment is shown in Fig. 9b. The response of precipitation to the ADE and AIE is a northward shift of the ITCZ and an enhancement of precipitation over Central America. The precipitation response to the perturbation in surface pressure over North America and the Atlantic Ocean is discussed 
above. The circulation and associated precipitation perturbations are modest in the ADE only simulations and substantially greater in the AIE only and combined ADE and AIE simulations. Column moisture convergence anomalies coincide with the precipitation anomalies reflecting the ITCZ shift and enhanced convection over Central America and the Caribbean. This leads to a large positive perturbation in precipitable water throughout Central America, the Caribbean and the southern United States, and a decrease in precipitable water throughout western South America and the adjacent southeast Pacific Ocean.

\section{Summary}

The impact of aerosol perturbations on regional radiative forcing, circulation patterns, and precipitation is explored over the Americas during boreal summer in an ensemble set of GCM simulation experiments. The response is diagnosed from the difference between simulations where climatological aerosol concentrations are doubled and halved over the selected land areas of North America, South America, Africa, and India. The model includes parameterizations for radiative interactions of aerosols under clear-sky conditions (the ADE) and parameterized aerosol nucleation of liquid and ice clouds (the AIE). Separate experiments are performed to investigate the impacts of the ADE and AIE individually and combined.

Both the ADE and the AIE yield net radiative cooling at the top of the atmosphere and the surface over both South America and North America. In both cases the surface forcing exceeds the TOA forcing, meaning there is a net radiative heating of the atmosphere. The heating results from direct aerosol absorption of solar radiation. The cloud greenhouse effect is enhanced by an increase in high cloud amount, however the increase in low cloud amount attributable to the AIE leads to a greater LW heating of the surface and a net LW cooling of the atmosphere. At least a portion of the increase in high cloud amount, in particular the increase simulated over North Africa, is a consequence of an increase in ice nuclei, as well as a suppression of the warm rain process in the lower part of convective clouds causing increased vertical transport of cloud condensate in convective updrafts. Changes in cloud amount also reflect changes in the regional circulation. In this study, we are unable to quantitatively separate the contribution owing to the microphysical modification of clouds from any contribution owing to changes in the regional circulation.

The response over the Americas is also likely impacted by the substantial response of clouds over the low latitude North Atlantic Ocean. A large LW heating perturbation results from the advection of enhanced upper-level cloud generated by the AIE over Africa in response to the increase in dust, which act as ice nuclei in the model. This cloud condensate is produced over the continent and transported over the
Atlantic Ocean by the upper-tropospheric winds. The LW heating perturbation over the ocean promotes a northward shift of the ITCZ over the Atlantic Ocean and northern South America. This feature, together with the depression of the seasonal low pressure minimum over North America results in a strong southerly wind anomaly that spans the Americas along $15 \mathrm{~N}$ latitude enhancing precipitation throughout Central America and enhancing convergence in the North American monsoon region.

These results represent a sensitivity study to strong aerosol perturbations in four selected regions of known high aerosol loading owing to industry, agriculture, and forest burning of anthropogenic origin. In light of the known long range transport of aerosols and the widespread response over surrounding oceans, and even the remote Atlantic Ocean, to aerosol perturbations over land, these experiments should be followed up with perturbations of global aerosols. Furthermore, the results presented here may be dependent on the specific model physics implemented in the aerosol, cloud and convection parameterizations employed in this model. Additional sensitivity tests of model parameters as well as intercomparisons with other global models are warranted.

Acknowledgements. Support for this study was provided by the NASA Interdisciplinary Science program and technical officer Hal Maring. Support for the Deserts to Monsoons meeting was supported by the NASA Grant: NNX06AF30G - Global Environmental Change-hazards and regional impacts, and support by the technical officers Don Anderson and Lucia Tsaoussi.

Topical Editor F. D'Andrea and the authors thank two anonymous referees for their help in evaluating this paper.

\section{References}

Albrecht, B. A.: Aerosols, Cloud Microphysics, and Fractional Cloudiness, Science, 245, 1227-1230, 1989.

Chin, M., Ginuox, P., Kinne, S., Torres, O., Holben, B. N., Duncan, B. N., Martin, R. V., Logan, J. A., Higurashi, A., and Nakijima, T.: Tropospheric Aerosol Optical Thickness from the GOCART Model and Comparisons with Satellite and Sun Photometer Measurements, J. Atmos. Sci., 59, 461-483, 2002.

Chou, M.-D. and Suarez, M. J.: An efficient thermal infrared radiation parameterization for use in general circulation models, NASA Tech. Memo. 104606, vol. 3, 85 pp., NTIS N95-15745, 1994.

Chou, M. D. and Suarez, M. J.: A Solar Radiation Parameterization for Atmospheric Studies, NASA Tech. Memo. 104606, vol. 15, 38 pp, 1999.

Chung, C. E., Ramanathan, V., and Kiehl, J. T.: Effects of the South Asian absorbing haze on the Northeast Monsoon and surface-air heat exchange, J. Climate, 15, 2462-2476, 2002.

Dubovik, O., Holben, B., Eck, T. F., Smirnov, A., Kaufman, Y. J., et al.: Variability of absorption and optical properties of key aerosol types observed in worldwide locations, J. Atmos. Sci., 59, 590608, 2002.

Easter, R. C., Ghan, S. J., Zhang, Y., Saylor, R. D., Chapman, E. G., et al.: MIRAGE: Model description and evalua- 
tion of aerosols and trace gases, J. Geophys. Res., 109, D20210, doi:10.1029/2004JD004571, 2004.

Fountoukis, C. and Nenes, A.: Continued development of a cloud droplet formation parameterization for global climate models, J. Geophys. Res., 110, D11212, doi:10.1029/2004JD005591, 2005.

Hansen, J., Sato, M., Ruedy, R.: Radiative forcing and climate response, J. Geophys. Res., 102, 6831-6864, 1997.

Haywood, J. M., Ramaswamy, V., and Soden, B. J.: Tropospheric aerosol climate forcing in clear-sky satellite observations over the oceans, Science, 283, 1299-1303, 1999.

Hobbs, P. V. and Radke, L. F.: Cloud condensation nuclei from a simulated forest fire, Science, 163, 279-280, 1969.

Hobbs, P. V.: Effects of Aerosols on Clouds and Radiation, in: Global Energy and Water Cycles, edited by: Browning, K. A. and Gurney, R. J., p. 91-99, Camb. Univ. Press, 1999.

Holben, B. N., Tanré, D., Smirnov, A., Eck, T. F., Slutsker, I., et al.: An emerging ground-based aerosol climatology: Aerosol optical depth from AERONET, J. Geophys. Res., 106(D11), 1206712097, 2001.

Kalnay, E., Kanamitsu, M., Kistler, R., Collins, W., Deaven, D., Gandin, L., Iredell, M., Saha, S., White,G., Woollen, J., Zhu, Y., Chelliah, M., Ebisuzaki, W., Higgins, W., Janowiak, J., Mo, K. C., Ropelewski, C., Wang, J., Leetmaa, A., Reynolds, R., Jenne, R., and Joseph, D.: The NCEP/NCAR 40-year reanalysis project, B. Am. Meteorol. Soc., 77, 437-471, 1996.

Kaufman, Y. J. and Fraser, R. S.: The effect of smoke particles on clouds and climate forcing, Science, 277, 1636-1639, 1997.

Kaufman, Y. J. and Koren, I.: Smoke and Pollution Aerosol Effect on Cloud Cover, Science, 313, 655-658, 2006.

Khvorostyanov, V. I. and Curry, J. A.: Toward the theory of stochastic condensation in clouds. Part I: a general kinetic equation, J. Atmos. Sci., 56, 3985-3996, 1999a.

Khvorostyanov, V. I. and Curry, J. A.: Toward the theory of stochastic condensation in clouds. Part II: analytical solutions of the gamma-distribution type, J. Atmos. Sci., 56, 3997-4013, 1999 b.

Koren, I., Kaufman, Y. J., Rosenfeld, D., Remer, L. A., and Rudich, Y.: Aerosol invigoration and restructuring of Atlantic convective clouds, Geophys. Res. Lett., 32, L14828, doi:10.1029/2005GL023187, 2005.

Koren, I., Marins, J. V., Remer, L. A., and Afargan, H.: Smoke invigoration versus inhibition of clouds over the Amazon, Science, 321, 946-949, 2008.

Lau, K.-W. and Kim, K.-M.: Observational relationship between aerosol and Asian monsoon circulation rainfall, Geophys. Res. Lett., 33, L21810, doi:10.1029/2006GL027546, 2006.

Lau, K.-M., Kim, M.-K., and Kim, K.-M.: Asian summer monsoon anomalies induced by aerosol direct forcing - the role of the Tibetan Plateau, Clim. Dynam., 36(7-8), 855-864, doi:10.1007/s00382-006-10114-z, 2006.

Liu, X. and Penner, J. E.: Ice nucleation parameterization for global models, Meteorol. Z., 14(4), 499-514, 2005.

Lohmann, U., Stier, P., Hoose, C., Ferrachat, S., Kloster, S., Roeckner, E., and Zhang, J.: Cloud microphysics and aerosol indirect effects in the global climate model ECHAM5-HAM, Atmos. Chem. Phys., 7, 3425-3446, 2007, http://www.atmos-chem-phys.net/7/3425/2007/.

Ming, Y., Ramaswamy, V., Donner, L. J., Phillips, V. T. J., Klein, S. A., et al.: Modeling the interactions between aerosols and liquid water clouds with a self-consistent cloud scheme in a general circulation model, J. Atmos. Sci., 64, 1189-1209, 2007.

Moura, A. D. and Shukla, J.: On the dynamics of droughts in Northeast Brazil: Observations, theory and numerical experiments with a General Circulation Model, J.Atmos. Sci., 38, 2653-2675, 1981.

Ramanathan, V., Crutzen, P. J., Kiehl, J. T., and Rosenfeld, D.: Aerosols, climate, and the hydrological cycle, Science, 294, 2119-2124, 2001.

Reynolds, R. W., and Smith, T. M.: Improved Global Sea Surface Temperature Analyses Using Optimum Interpolation, J. Climate, 7, 929-948, 1994.

Rosenfeld, D. and Woodley, W. L.: Deep convective clouds with sustained supercooled liquid water down to $-37.5^{\circ} \mathrm{C}$, Nature, 405, 440-442, 2000.

Rotstayn, L. D. and Lohmann, U.: Tropical rainfall trends and the indirect aerosol effect, J. Climate, 15, 2103-2116, 2002.

Seifert, A. and Beheng, K. D.: A double-moment parameterization for simulating autoconversion, accretion and self collection, Atmos. Res., 59, 265-281, 2001.

Sud, Y. C. and Walker, G. K.: Microphysics of clouds with the relaxed Arakawa-Schubert scheme (McRAS). Part I: Design and evaluation with GATE phase III data, J. Atmos. Sci., 56, 31963220, 1999a.

Sud, Y. C. and Walker, G. K. Microphysics of clouds with the relaxed Arakawa-Schubert scheme (McRAS). Part II: Implementation and performance in GEOS II GCM, J. Atmos. Sci., 56, 3221-3240, $1999 b$.

Sud, Y. C. and Lee, D.: Parameterization of aerosol indirect effect to complement McRAS cloud scheme and its evaluation with the 3year ARM-SGP analyzed data for single column models, Atmos. Res., 86, 105-125, 2007.

Sud, Y. C., Wilcox, E., Lau, W. K.-M., Walker, G. K., Liu, X.-H., Nenes, A., Lee, D., Kim, K.-M., Zhou, Y., and Bhattacharjee, P. S.: Sensitivity of boreal-summer circulation and precipitation to atmospheric aerosols in selected regions - Part 1: Africa and India, Ann. Geophys., 27, 3989-4007, 2009, http://www.ann-geophys.net/27/3989/2009/.

Takemura, T., Nozawa, T., Emori, S., Nakajima, T. Y., and Nakajima, T.: Simulation of climate response to aerosol direct and indirect effects with aerosol transport-radiation model, J. Geophys. Res., 110, D02202, doi:10.1029/2004JD005029, 2005.

Yoshioka, M., Mahowald, N. M., Conley, A. J., Collins, W. D., Fillmore, D. W., et al.: Impact of desert dust radiative forcing on Sahel precipitation: Relative importance of dust compared to sea surface temperature variations, vegetation changes, and greenhouse gas warming, J. Climate, 20, 1445-1467, 2007.

Twomey S.: Pollution and the planetary albedo, Atmos. Environ., 8, 1251-1256, 1974.

Wilcox, E. M., Roberts, G., and Ramanathan, V.: Influence of aerosols on the shortwave cloud radiative forcing from north Pacific Oceanic Clouds: Results from the Cloud Indirect Forcing Experiment (CIFEX), Geophys. Res. Lett., 33, L21804, doi:10.1029/2006GL027150, 2006.

Zhang, Y., Fu, R., Yu, H., Dickinson, R. E., Juarez, R. N., et al.: A regional climate model study of how biomass burning aerosol impacts land-atmosphere interactions over the Amazon, J. Geophys. Res., 113, D14S15, doi:10.1029/2007JD009449, 2008. 